\title{
Novos atores e repertórios de ação no movimento pelos direitos do adolescente: repensando a institucionalização
}

\author{
New actors and action repertoires rights movement in adolescents: rethinking the \\ institutionalization
}

\author{
Maria do Carmo Albuquerque*
}

\begin{abstract}
Resumo:
A "institucionalização" dos movimentos sociais tem sido associada a problemas como o corporativismo e a cooptação, tanto pela literatura como por atores que os integram. Tais problemas são apontados como ameaças à autonomia e à novidade, atribuídas aos movimentos no processo de reconstrução e aprofundamento da democracia no Brasil. No entanto, à medida que cresce a institucionalização democrática, os atores institucionais e os formatos institucionais de ação estão cada vez mais presentes nos movimentos. O Movimento pelos Direitos da Criança e do Adolescente (MDCA) atua na criação e controle social de políticas públicas, destacando-se os seus repertórios de ação institucional. Com as tendências atuais de contratação de organizações sociais para a prestação de serviços, o Movimento vem incluindo numerosas entidades conveniadas com o Estado, especialmente na política socioeducativa em meio aberto. Portanto, o presente artigo analisa atores que integram o Movimento pelos Direitos da Criança e Adolescente em São Paulo, somado a esforços que buscam examinar atentamente a ação institucional dos movimentos sociais no Brasil, identificando alguns dos dilemas e desafios atuais ligados a essa atuação.
\end{abstract}

Palavras-chave: Movimento Social; Repertórios de ação; Institucionalização; Cooptação; Direitos da criança e adolescente; Adolescente em conflito com a lei; Controle social; Política socioeducativa.

\begin{abstract}
:
The "institutionalization" of social movements has been associated to problems like corporatism and cooptation, both by the literature and by actors that integrate them. These problems are mentioned as threats to autonomy and novelty attributed to movements in the process of reconstruction and deepening of democracy in Brazil. However, as it grows the institutionalization democratic, institutional actors and institutional forms of action are ever more present in the movements. The Movement for the Rights of the Child and Adolescent acts in creation and social control of public policies, especially their repertoires of institutional action. With the current trends of contracting social organizations to provide services, the Movement has included
\end{abstract}

\footnotetext{
* Mestre pela Unicamp em Ciência Política, doutora pela USP em Integração da América Latina, pesquisadora na área de movimentos sociais, políticas públicas, participação e controle social. Integrante do Núcleo de estudos Democracia e ação coletiva do CEBREAP (NDAC) mcarmoa@gmail.com
} 
numerous entities contracted by the state, especially in policies for adolescent offenders. The article looks at actors which integrate the Movement of Rights of the Child and Adolescents in São Paulo and adds up to efforts that seek to examine the institutional action of social movements in Brazil, identifying some of the dilemmas and challenges related to this action.

Keywords: Social Movement; Repertoires of action; Institutionalization; Cooptation; Rights of the child and adolescent; Adolescent in conflict with the law; Social control; Socioeducative Policy.

\section{Introdução}

A "institucionalização" dos movimentos sociais tem sido vista com receio e associada a problemas como o corporativismo, a burocratização e a cooptação tanto pelos autores que os estudam como pelos atores que os integram. Tais problemas são apontados como ameaças à autonomia e à novidade atribuídas aos movimentos como atores fundamentais no processo de reconstrução e aprofundamento das democracias na América Latina e no Brasil.

No entanto, à medida que cresce a institucionalização democrática nesses países, os atores institucionais e os formatos institucionais de ação têm sido cada vez mais presentes nos movimentos.

Este artigo busca, por meio do contraste entre as avaliações realizadas por ativistas e pela literatura acadêmica, escapar de uma visão que associa, de forma homogênea, à institucionalidade aos problemas citados e distinguir diferentes aspectos dessa relação, procurando identificar com mais acuidade o significado e o lugar que ocupa a ação institucional no repertório do movimento.

Este estudo focaliza um movimento que se caracteriza por intensa ação institucional, uma vez que tem objetivos fortemente ligados à conquista de direitos e de políticas públicas o movimento social pelos direitos da criança e do adolescente (aqui movimento DCA Departamento de Controle Acadêmico). Foca-se o estudo na cidade de São Paulo, onde atores tradicionais do movimento DCA ocupam hoje um lugar institucional na execução de medidas socioeducativas para adolescentes em conflito com a lei.

Inicialmente, é constatado que a literatura sobre os movimentos sociais e ação coletiva destaca seu papel relevante nos processos de luta contra as ditaduras e de construção 
democrática na América Latina. Alargaram a construção da democracia para além da redemocratização formal do Estado (DAGNINO, PANFICHI; OLVEIRA, 2006). Por isso, os chamados "novos movimentos sociais" foram saudados como inovações democráticas que escaparam da tutela do Estado. Como aponta Paoli (1995, p. 27), os novos movimentos "não se referenciavam diretamente às estruturas institucionais de poder e representação política partidos, governo, Estado - nem aos atores 'clássicos'”, no entanto, sua originalidade, sua novidade, encontrava-se na "aspiração de um poder civil e cidadão" em "escapar de uma institucionalidade estatal" que era "tutelar, autoritária e burocrática" (PAOLI, 1995, p.32).

A literatura internacional sobre a ação coletiva, como destacam Abers, Serafim e Tatagiba (2011, p. 8), também enfatizou principalmente "a relação entre Estado e movimentos sob a chave do conflito", dando centralidade aos "repertórios de protesto". Os esforços das autoras se somam aos atuais, ${ }^{1}$ que buscam avançar na compreensão da ação institucional dos movimentos.

No Brasil, os movimentos sociais se destacam² pela reivindicação e participação na construção de sistemas descentralizados de políticas sociais, que preveem a participação formal da sociedade em seu controle público. Uma vasta literatura foi desenvolvida, analisando-se então essa nova democracia participativa institucionalizada, destacando ora suas virtudes, ora seus limites. Assim, os movimentos sociais no Brasil se veem tensionados pela sua proposta de participar nas políticas públicas e pelo receio de serem "engolidos" pelos males dos espaços e procedimentos institucionais de poder - o Estado e os partidos políticos.

Essa tensão será nosso ponto inicial, partindo de depoimentos que afirmam com clareza a importância da ação institucional, para os movimentos, sem deixar de apontar receios, problemas e ameaças à sua autonomia, vitalidade e "rebeldia".

\footnotetext{
${ }^{1}$ Entre os esforços, destaca-se o citado artigo de Abers, Serafim e Tatagiba (2011), bem como Tatagiba (2011), Abers e Bülow (2011), Carlos (2012), Gurza Lavalle e Isunza Vera (2010), Almeida (2011), e o dossiê organizado por Ilse Scherer-Warren e Lígia H. H. Lüchmann (2011), a partir do Seminário Movimentos sociais, participação e democracia.

${ }^{2}$ Inês González Bombal (2003, p. 355), analisando processos de incidência da sociedade civil em políticas públicas a partir de estudos de caso em 3 países, afirma, em relação ao Brasil, que "nada semelhante, a essa escala, existe nos outros países analisados". Albuquerque (2007) identifica a mesma característica estudando 5 países no cone sul.
} 
“Participar vale a pena, mas..." é o título do artigo de José Szwako (2012), fruto de extensa pesquisa com atores dos movimentos sociais brasileiros que participam dos novos espaços de controle social sobre as políticas públicas, como as conferências e conselhos. Da mesma forma, os seguintes depoimentos afirmam uma articulação necessária entre a ação institucional e extrainstitucional dos movimentos, sem deixar de apontar um "mas", o qual identifica ameaças e problemas.

Evaniza Rodrigues, ${ }^{3}$ militante do movimento nacional por moradia popular, reivindica a importância da participação em espaços institucionais e se posiciona contra a dicotomia entre o fazer (a ação na "rua", ação de protesto, do "queimar pneus") e o pensar a formulação de propostas e sua apresentação no lugar institucional.

Acho que as pessoas querem do movimento uma postura que nós não temos. A maior parte destas críticas vem ou da academia, ou de ONGs, de entidades que estão fora do dia a dia do movimento e até de partidos políticos. [...] é a divisão entre o pensar e o fazer: Podemos ser um movimento que vai para a rua queimar pneus [...], mas não podemos ser movimento que formula propostas e apresenta em conselhos, em uma instância de deliberação ou no parlamento? Vinte anos depois, continuam com a mesma postura: quando ocupamos um espaço desses estamos "pelegando" e quando estamos na rua não estamos. É uma questão bem clássica! Mas claro que ocupar espaços institucionais demanda tempo e trabalho e se não se tem condição, apoio, força para multiplicar a ação... a mesma energia é dispersa. $O$ aumento da luta não necessariamente aumenta a capacidade de organização do movimento. Uma conquista te absorve uma energia tal que te tira a capacidade de fazer outra.

Evaniza questiona a histórica e a clássica separação entre os momentos de confronto e os momentos de elaboração de propostas e sua negociação com poderes institucionais no parlamento, no executivo e nos conselhos, que seriam ameaçados pela possibilidade do movimento "pelegar", amortecendo conflitos e submetendo-se aos atores estatais.

${ }^{3}$ Evaniza Rodrigues, da União Nacional por Moradia Popular. Entrevista realizada pela equipe da Escola da Cidadania, Instituto Pólis, em 25/3/2008.

${ }^{4}$ Pelego é o couro do carneiro com lã, que é colocado como assento sobre o cavalo para amaciar o contato com o cavaleiro. A expressão "pelegar" se refere às ações dos sindicalistas que buscam amaciar a relação entre trabalhadores e patrões, defendendo as posições dos últimos. 
No entanto, os atores sociais reconhecem um "mas", reconhecem novas dificuldades, velhas ameaças que se intensificam. Os velhos temores de que a institucionalidade estatal possa "apelegar", amansar, tutelar ou cooptar os movimentos sociais que continuam presentes.

É o que aponta Renato Roseno, ${ }^{5}$ militante do movimento nacional pelos direitos da criança e adolescente (movimento DCA), analisando a sociedade civil que atua nas políticas DCA:

A sociedade que sai do ajuste neoliberal brasileiro é uma sociedade à direita da sociedade que entrou [...]. É verdade sim que várias organizações de sociedade civil, nascidas no processo de inovação democrática, acabaram sendo terceirizadas do Estado. [...] Com a saída da cooperação internacional, a maioria das nossas organizações acaba tendo que tecer estratégias de sobrevivência que recaem nos programas governamentais. [...] Se, por um lado, não era correto depender exclusivamente da cooperação internacional, por outro lado também não é correto, do ponto de vista do exercício das nossas autonomias, ter as nossas organizações em que os seus orçamentos $100 \%$ deles sejam governamentais. [...] Aprisionamos a nossa rebeldia no Conselho, no Fórum e no diálogo com o aparelho do Estado? [...] Como é que nós nos educamos coletivamente para dizer que o que move a história é a rebeldia? Ou vocês viram alguma sociedade na história humana distribuir riqueza que não fosse pela rebeldia, pelo conflito? (FNDCA, 2010, p. 21, 41).

As falas de Evaniza e Renato revelam a necessidade de investigar com mais profundidade o fenômeno chamado de "institucionalização" dos movimentos. Os entrevistados apontam questões como a necessária articulação entre a ação na rua e no espaço institucional, entre os momentos de confronto e de elaboração, alertando, também, para o perigo de o movimento "aprisionar a sua rebeldia", perder a autonomia, a capacidade de conflito, "pelegar" e assumir posições governamentais ou projetos políticos à "direita", ou neoliberais. Indicam, nesse contexto, alguns "nós" que precisam ser desatados e investigados como a demanda de tempo, energia e trabalho para as novas estratégias de ação, a questão do financiamento das organizações sociais e sua dependência financeira da cooperação internacional ou do Estado.

\footnotetext{
${ }^{5}$ Renato Roseno foi conselheiro do Conanda (Conselho Nacional dos Direitos da Criança e do Adolescente), como representante da ANCED (Associação Nacional dos Centros de Defesa da Criança e do Adolescente) entre 2005 e 2006. A intervenção é de 2010, em Seminário do Fórum Nacional DCA sobre Políticas Públicas.
} 
Este artigo objetiva se somar aos esforços atuais para avançar na compreensão da ação institucional do movimento e suas interações tanto conflitivas como "colaborativas" com o sistema político. Conforme Almeida (2011, p. 13)

[...] essas abordagens sugerem a construção de um olhar que privilegie a fluidez das relações entre Estado e sociedade civil, os diversos modos pelos quais seus agentes interagem e se condicionam mutuamente, em distintos espaços e temporalidades.

O artigo pende a iluminar a presença de atores e estratégias de ação institucionais ao lado dos atores e estratégias informais, identificando lugares mais e menos formais e institucionalizados e momentos mais e menos conflitivos e colaborativo-propositivos. Busca, também, desdobrar a questão da institucionalização, localizando onde estão os "nós" que minariam a vitalidade rebelde dos movimentos, e identificar desafios analíticos para aprofundar este estudo. Para tanto, são analisadas opiniões expressas por lideranças nacionais de movimentos sociais e por ativistas do movimento DCA em São Paulo. ${ }^{6}$

Em seu depoimento, Evaniza afirma a importância da articulação entre a ação societal de protesto, o movimento "vai para a rua, queimar pneus", e a ação institucional, formular e apresentar propostas em espaços institucionais como os conselhos e o parlamento.

Já Renato Roseno focaliza alguns atores do movimento que se institucionalizam assumindo vínculos financeiros com o Estado, apontando o problema da retirada de outros vínculos, como a cooperação internacional, e a dependência financeira, muitas vezes total, do Estado, principalmente quando esse está sob um projeto político de direita, ou neoliberal; associa também a heterogeneidade de vínculos e a presença da cooperação internacional com a manutenção da autonomia e "rebeldia" do movimento.

Em vez de associar a "institucionalização" como um todo ao perigo do movimento se "apelegar", amortecer conflitos, submeter-se à lógica institucional estatal e ter sua rebeldia

\footnotetext{
${ }^{6} \mathrm{Na}$ pesquisa docente que fundamente este artigo, foi realizado o acompanhamento das reuniões do Fórum Municipal de Defesa dos Direitos da Criança e do Adolescente (FMDDCA) e outros eventos do movimento DCA em São Paulo nos anos de 2011 e 2012, sendo entrevistadas 7 pessoas entre ativistas e integrantes da política socioeducativa em São Paulo. Foram também recuperadas outras entrevistas e depoimentos de lideranças dos movimentos. Iniciou-se ainda o acompanhamento da Articulação das entidades executoras de Medidas Socioeducativas em Meio Aberto (MSE-MA) em São Paulo.
} 
aprisionada, procura-se, distinguindo diferentes aspectos da "institucionalização", identificar onde estão os "nós" nas relações entre a ação conflitiva ou rebelde e as ações institucionalizadas do movimento.

O artigo vai seguir estas três pistas e mostrar: a) que a ação institucional é uma característica permanente do movimento DCA e não é um perigo em si mesma, associada de forma homogênea com a cooptação e o corporativismo; b) distinguir diferentes aspectos, conflitivos e colaborativos, nos repertórios de ação institucional; c) analisar o processo de institucionalização de atores do movimento que se dá pelas relações de conveniamento com o Estado. Esses dois aspectos buscam identificar onde estão os "nós" ou ameaças à vitalidade, autonomia ou rebeldia do movimento.

\section{Ação institucional e extrainstitucional no movimento DCA}

Mesmo se forem considerados os antecedentes históricos, nacionais e internacionais, o movimento pelos direitos da infância e juventude sempre foi marcado pela presença de atores e de formas de ação societais e institucionais, que combinam repertórios de protesto e conflito, com repertórios mais "pacíficos", propositivos e colaborativos.

A Declaração de Genebra sobre os Direitos da Criança, de 1924, foi elaborada por organizações sociais, ${ }^{7}$ que a apresentaram para ser adotada pela Liga das Nações. Já nesse momento, combinaram-se estratégias de elaboração de propostas, no interior do espaço societal, e estratégias de negociação no espaço institucional. Outro organismo institucional internacional, a Organização Internacional do Trabalho (OIT), relaciona-se, nesse mesmo momento, com as lutas contra o trabalho infantil. Articula-se atores societais em ações conflitivas, como a atuação de comitês de inspeção e monitoramento da situação do trabalho infantil e a "Marcha Global contra o Trabalho Infantil", iniciada em 1997 (ALBUQUERQUE, 2007). Outros atores institucionais do sistema das Nações Unidas como a Organização dos Estados Americanos (OEA) com seu Instituto Interamericano del Niño (INN) e o Fundo das

\footnotetext{
${ }^{7}$ A Declaração foi elaborada e proposta por duas organizações sociais, Save the Children e União Internacional de Auxílio à Criança, para o Comitê de Proteção da Infância da Liga das Nações, criada em 1919, antecedendo a criação da ONU.
} 
nações Unidas (UNICEF) se destacaram na construção de um paradigma de direitos para a infância e juventude. A presença de atores societais é contínua e se destaca na Convenção Internacional sobre os Direitos da Criança (CDC), elaborada por um grupo de ONGs e adotada pela Organização das Nações Unidas (ONU) em 1989. O Brasil está à frente nesse processo, e já em 1990 aprova o Estatuto da Criança e Adolescente (ECA).

A luta por um paradigma e uma política de direitos é travada contra o chamado "paradigma menorista", que se caracterizou, ao longo dos séculos, por diferenciar crianças e "menores" - aqueles em "situação irregular". 8 Nas lutas contra este paradigma também se destacaram atores e ações societais e institucionais. Em 1956, a Ação Social Arquidiocesana, organização católica que atuava na atenção à infância no Rio de Janeiro, elaborou esboço de lei para a extinção do SAM e criação de uma nova política. As críticas, avaliações e mobilizações envolveram a sociedade, organismos internacionais como Unicef e o poder legislativo, mediante CPI (Comissão Parlamentar de Inquérito) do Menor Abandonado (1975), que se desdobrou nos estados em várias Comissões Especiais de Inquéritos (PEREIRA, 1996, p. 63). Nota-se, assim, a atuação de atores societais e institucionais, em lugares societais ou institucionais, e em momentos mais "pacíficos", como a elaboração de uma crítica ou proposta, ou mais conflitivos, como a sua divulgação na mídia ou sua investigação numa CPI.

É na sequência dessas lutas que emerge, no Brasil, o movimento social pelos direitos da criança e adolescente (movimento DCA), no contexto da emergência de novos atores sociais que lutam contra a ditadura, por direitos humanos e direitos sociais e por uma nova Constituição federal. A Pastoral do Menor, o Movimento Nacional de Meninos e Meninas de Rua (MNMMR), educadores de rua, assistentes sociais, psicólogos, médicos, advogados, defensores públicos, promotores, e suas organizações, destacaram-se na elaboração de novas metodologias de intervenção e propostas de programas e nas negociações políticas que originaram o ECA.

\footnotetext{
${ }^{8}$ Os menores em situação irregular, carentes, abandonados ou infratores, eram confinados em instituições que não diferenciavam essas situações. Esse paradigma se liga no Brasil aos primeiros Códigos de menores, de 1927 e de 1979, e a serviços que atendiam os menores "abandonados" e "infratores", como o Serviço de Assistência a Menores (SAM) criado em 1941 e a Fundação Estadual para o Bem Estar do Menor (Febem), criadas a partir de 1964 pela Política do Bem-Estar do Menor (PNBEM).
} 
O movimento se organiza desde os anos 1980, por meio de Fóruns, no plano nacional, estadual e municipal. ${ }^{9}$ Em São Paulo, são organizados ainda numerosos fóruns regionais. Os fóruns são articulações bastante informais, constituídos por ativistas e por organizações ou entidades ${ }^{10}$ da sociedade civil, entre as quais algumas informais e outras institucionalizadas.

Este grande ciclo de mobilização do movimento tem como pico a aprovação do artigo 227 da Constituição de 1988 e do ECA, em 1990, normativas que instituem o paradigma da "proteção integral" (Artigo 1ㅇ do ECA), também conhecido como "paradigma garantista", focado na afirmação da criança e adolescente como sujeitos de direitos, considerados “prioridade absoluta" (artigo 4으).

\section{O Repertório de ações do movimento DCA}

Para analisar as estratégias ou formas de ação do movimento, utiliza-se o conceito de repertório desenvolvido por Charles Tilly (apud TARROW, 2009, p. 51), que se refere ao "repertório disponível de ações coletivas para uma população" ou às "maneiras através das quais as pessoas agem juntas em busca de interesses compartilhados". Tilly considera que os movimentos escolhem e aprendem formas de ação legitimadas por outros movimentos como as marchas e as petições. Estas escolhas se dão dentre o repertório já conhecido e também pela experimentação e combinação de práticas diversas em novas formas de se organizar, mobilizar apoio e articular demandas (TILLY, 1992; TARROW, 2009). O conceito está muitas vezes associado ao "repertório de confronto", embora os movimentos sociais no Brasil, como nos exemplos já citados, não escolham apenas o confronto como maneira, forma ou estratégia de ação. É nesse sentido que Abers, Serafim e Tatagiba (2011, p. 4) apresentam o conceito de

\footnotetext{
${ }^{9}$ O Fórum Nacional DCA foi criado em 1980 e a sua página na web (http://www.forumdca.org.br) registra 27 fóruns estaduais e 53 entidades filiadas. O Fórum Estadual de São Paulo pode ser conhecido pelo site http://forumestadualdcasp.blogspot.com.br e o Fórum Municipal DCA de São Paulo pelo http://www.forummunicipaldcasp.org.br.

10 Neste trabalho, utiliza-se a palavra entidade com o sentido de uma organização social formalizada juridicamente. As organizações sociais são entendidas aqui como aquelas que não necessariamente possuem esse grau de institucionalização, podendo apresentar apenas uma organização interna como, por exemplo, a definição de uma coordenação, os fóruns são organizações desse tipo.
} 
"repertório de interação", buscando incluir diversas formas, práticas e estratégias de interação com o Estado entre aquelas escolhidas pelos movimentos para integrar o seu repertório.

Optou-se, aqui, por utilizar o conceito de repertório de ações, incluindo tanto as ações de confronto como as de interações mais propositivas e colaborativas. Dentro da noção de repertório, deseja-se ainda distinguir lugares e momentos da ação. A ação do movimento pode ocorrer em lugares societais e institucionais - aqueles formalizados dentro da institucionalidade estatal. Podem, ainda, ocorrer momentos mais conflitivos e menos conflitivos, mais "pacíficos", propositivos ou colaborativos.

No período mais mobilizado do ciclo que se descreve anteriormente ainda não havia os espaços institucionais de participação que caracterizam a chamada "democracia participativa" brasileira. No entanto, já era forte a presença de estratégias institucionais de ação, articuladas com estratégias societais. Pode-se identificar no movimento DCA um repertório de ações institucionais e extrainstitucionais, momentos de mobilização e confronto e momentos de elaboração e colaboração com o Estado na construção de políticas públicas.

Atores e lugares institucionais e societais combinam-se de todas as maneiras com momentos mais "pacíficos", de elaboração de propostas e momentos mais conflitivos, de confronto e presença nas ruas e meios de comunicação. Distingue-se, então, 3 categorias para a análise da chamada "institucionalização do movimento" - os atores societais e institucionais ou estatais, os lugares societais e institucionais e os momentos mais pacíficos ou colaborativos e mais conflitivos.

É possível identificar a ação de atores societais em lugares societais e em momentos "pacíficos" como as reuniões do MNMMR ou da Pastoral do Menor, como o desenvolvimento de novas metodologias dos educadores de rua ou as reuniões do grupo de trabalho para a elaboração da Emenda popular constituinte "Criança Prioridade Nacional”.

Atores societais também se fazem presentes em lugares societais, como as ruas e a mídia, em momentos de demonstração de força, mostrando seus valores e sua mobilização na 
Campanha nacional "Criança Constituinte" e na coleta de 1,5 milhões de assinaturas em todo o país para a emenda popular que originou o artigo 227 da nova Constituição Federal. ${ }^{11}$

No entanto, estão presentes atores estatais como a Frente Nacional de Defesa dos Direitos da Criança, constituída, segundo Rosemary Pereira (1996, p. 17), por "agentes municipalistas de perfil progressista". Atores societais e estatais também se fizeram presentes na Comissão para a Redação do ECA, onde, segundo Lorenzi (2007), houve a representação de três grupos expressivos: o "dos movimentos da sociedade civil”, o dos juristas (principalmente ligados ao Ministério Público) e o de técnicos de órgãos governamentais (notadamente funcionários da própria Fundação Nacional do Bem-Estar do Menor - Funabem).

Nesse período, porém, a atuação nos lugares institucionais de ação, como o Congresso Nacional, ainda é bastante informal e os atores societais buscam se fazer ouvir em diálogos mais "pacíficos" ou em negociações mais conflitivas.

A implementação do ECA, especialmente a construção de um Sistema descentralizado e participativo de Garantia de Direitos (SGDCA), ocupa fortemente o movimento DCA, que luta pelo desenho e reconhecimento dos espaços institucionais de participação, como os Conselhos Tutelares, os Conselhos de Direitos, ${ }^{12}$ as conferências e os Fundos da Criança e Adolescente no nível federal, estadual e municipal. Ocupar esses espaços, organizar as conferências e as eleições têm sido fortes momentos de embate com o Estado e complexos momentos de negociações de alianças societais e institucionais.

Abrem-se, assim, novos lugares institucionais onde os atores societais podem exercer seu direito ao controle social sobre a política DCA, em todas as suas fases, desde a elaboração, a execução até a avaliação.

\section{Confrontos e cooptação}

\footnotetext{
${ }^{11}$ Ver Curso de Direitos Humanos - Módulo III. Conselho dos Direitos da Criança e do Adolescente. Unidade I - O Marco legal Internacional e Nacional dos Direitos da Criança e do Adolescente. Disponível em: <http://www.dhnet.org.br/dados/cursos/dh/cc/3/crianca/marco.htm>. Acesso em 05/11/2011.

${ }^{12}$ A própria definição do Sistema de Garantia de Direitos (SGDCA) é realizada no interior do Conselho Nacional de Direitos, o Conanda, que segue construindo as políticas nacionais DCA por meio de suas resoluções. Veja-se, entre 2005 e 2012, a construção das políticas para o adolescente em conflito com a lei (Sinase).
} 
Atores sociais da cidade de São Paulo relatam ${ }^{13}$ momentos mais propositivos e mais conflitivos nessa fase de conquista dos novos espaços institucionais - a instituição do Conselho Municipal (CMDCA), das Conferências de direitos e dos primeiros 20 Conselhos Tutelares. Conseguir sua primeira eleição, os espaços físicos para sua atuação, os salários para os Conselheiros Tutelares, tudo isso se inicia no final do mandato da prefeita petista Luiza Erundina, substituída em 1993 pelo prefeito Paulo Maluf, de um partido com projeto político extremamente conservador. ${ }^{14}$ Houve então momentos de embate extremamente conflitivos.

Nossos entrevistados se referem a esse período do movimento como muito vigoroso, difícil, desafiador. Momento que mobilizou apoios importantes da Igreja católica com ajuda de bispos ligados à Teologia da Libertação e da Pastoral do Menor, professores da PUC, juízes, defensores, entidades internacionais como UNICEF etc.

A participação do movimento nos conselhos e conferências municipais atravessou, até o momento, um governo petista e quatro governos de partidos mais conservadores (PP, DEM, $\left.\mathrm{PSDB}^{15}\right)$. Apesar de compartilhar em grande medida o projeto político ${ }^{16}$ do $\mathrm{PT}$, visto que vários de seus membros participam ou participaram do grupo "Setorial da Criança e Adolescente do PT", o movimento, especificamente o Fórum Municipal DCA, viveu momentos de confronto e fortes conflitos com o governo petista de Marta Suplicy, e com o Partido dos Trabalhadores.

Um desses momentos atravessou meses de 2003 e culminou na renúncia coletiva dos conselheiros municipais representantes da sociedade civil em março de $2004^{17}$ (SÃO PAULO, 2004). Outros momentos de confronto são relatados por um ex-conselheiro, que relata ter sofrido represálias quando não "fechou" com algumas propostas do partido: "para o PT quem não é aliado é inimigo". O entrevistado também relata que a chapa eleita em julho de 2012 foi articulada no "setorial" do PT, por integrantes de mandatos parlamentares do Partido. Comenta ainda que no governo Marta muita gente "foi cooptada para dentro do governo", e

\footnotetext{
${ }^{13}$ Entrevistados 4, 6 e 7.

14 Informações advindas das entrevistas 4, 6 e 7. Ver caracterização nas referências.

15 Partidos políticos brasileiros: Partido Progressista (PP), Partido Democratas (Dem), Partido da Social Democracia Brasileira (PSDB) e Partido dos Trabalhadores (PT).

${ }^{16}$ Ver a noção de projeto político e a referência a projeto político compartilhado em Dagnino (2006, p. 24, 38).

17 Os fatos estão documentados em Carta do FMDCA publicada no Diário Oficial do Estado de São Paulo (DOSP) de 09/04/2004.
} 
que era "difícil fazer a crítica". Nota-se que a perda de autonomia frente aos partidos ocorre tanto à esquerda como à direita, visto que, segundo o mesmo entrevistado, "Hoje quem elege os Conselhos Tutelares são os vereadores do PT, do PSDB".

As entrevistas também apontam o contrário: os governos Erundina e Marta Suplicy são citados com ênfase pelo apoio, Erundina pelo apoio à criação do primeiro Conselho de Direitos e primeiros Conselhos Tutelares, e Marta pela abertura de que as escolas municipais fossem usadas pelo movimento e pelo incentivo a que professores e outros profissionais participassem dos Fóruns e Conferências. Um entrevistado cita que hoje o "projeto político" do governo "dificulta muito" a participação, e que muita gente que "era ativa e militante" era "impedida de participar, amordaçada".

A dificuldade de participação nos espaços institucionais, nos governos mais conservadores, é enfatizada por todos os entrevistados, os quais se referem à "mordaça", ao impedimento de que organizações conveniadas participem dos Fóruns regionais, às chapas montada por governos para concorrer ao CMDCA, a um militante que passou a fazer parte do governo e sempre esteve liberado para atuar no Conselho e articular as chapas "governistas".

Identifica-se, ainda, numerosos ativistas que atravessam as fronteiras entre Estado e sociedade como, por exemplo, advogados que atuaram na sociedade civil e depois se tornaram promotores ou defensores públicos, militantes que se tornaram assessores de parlamentares ou funcionários no executivo. Essas travessias remetem à preocupação, apontada por Abers e Büllow (2011, p. 52) de aprofundar o estudo sobre "as numerosas formas de interação entre ativistas de movimentos sociais situados dentro e fora do Estado".

Em 2011, o Fórum Municipal viveu um forte momento de confronto com o governo municipal e com o CMDCA, denunciando o esvaziamento da Conferência municipal por falta do apoio prometido para o transporte e alimentação nas conferências regionais, que deveriam escolher os delegados para a municipal. Nota-se, por um lado, um ganho no comprometimento dos recursos públicos com a mobilização popular, mas, por outro lado, o movimento fica aprisionado na espera desse apoio. A dependência do movimento em relação a esses recursos e ao modo de funcionamento das instituições estatais que estruturam os conselhos e conferências foi, nesse contexto, um freio à participação. 
Percebe-se assim que a ação institucional é uma característica permanente do movimento DCA e que a vitalidade do movimento está ligada à possibilidade de combinar repertórios de ação societal e institucional.

O desequilíbrio entre essas duas formas de ação, com a crescente predominância de repertórios institucionalizados, parece introduzir alguns "nós" ou ameaças para a vitalidade do movimento nas dificuldades de lidar: a) com a lógica institucional e burocrática do Estado e b) com a força dos interesses e projetos políticos presentes em governos e partidos que se apresentam como ameaças de cooptação tanto à direita como à esquerda.

\section{A política socioeducativa e as entidades conveniadas}

Nesta seção, busca-se analisar um aspecto do ECA que tem sua implementação especialmente difícil: a garantia dos direitos do adolescente em conflito com a lei. Em São Paulo, esse se torna o foco de outro importante ciclo de mobilizações do movimento DCA. Percebe-se aqui repertórios de ação societal e institucional, com seus atores e lugares de ação societais e institucionais e com seus momentos de confronto e de elaboração propositiva e colaborativa. Mas, focaliza-se com mais detalhe outro aspecto no qual se localizam problemas ligados à "institucionalização" do movimento - a presença de atores societais que se institucionalizam e se vinculam ao Estado por meio de convênios para a execução de programas socioeducativos.

A política voltada para os adolescentes infratores é alvo de históricas mobilizações da sociedade civil que luta por direitos humanos. Em São Paulo, já após a aprovação do ECA, a Febem, nascida na antiga Política Nacional de Bem-Estar do Menor (PNBEM) dos anos 1960 e ainda marcada pelo paradigma menorista, torna-se o centro da luta contra os maus-tratos e torturas característicos do sistema penal juvenil brasileiro. As rebeliões e mortes do final dos anos 1990 são o início de um forte movimento pela extinção da Febem, ${ }^{18}$ que culmina com a

18 Em 1999 se constituiu o Grupo de Trabalho para o Reordenamento da Febem que elaborou um projeto entregue ao governador e à Secretaria de Justiça. O grupo era integrado por diversos movimentos sociais, 0 Sindicato dos Trabalhadores em Entidades de Assistência ao Menor e à Família do Estado (SITRAEMFA), a Subcomissão de Defesa dos Direitos da Criança e do Adolescente da Ordem dos Advogados do Brasil - Seção São Paulo, o Fórum Estadual de Defesa dos Direitos de Crianças e Adolescentes e outras organizações sociais 
sua conversão em Fundação CASA, em 2006. Organizações sociais locais, nacionais e internacionais, ${ }^{19}$ como a Anistia Internacional, e organismos das Nações Unidas como a Corte de Interamericana de Direitos Humanos da OEA mobilizam-se nesse processo. O Conselho estadual (Condeca), por meio de sua Deliberação 15, proíbe em 1999 a internação de adolescentes em uma das Unidades de internação. Também o poder legislativo estadual é mobilizado na ação de investigação e denúncias pela CPI da Febem, realizada entre 1997 e 1999 (CARDOSO, 2010).

Inicia-se então a descentralização da política socioeducativa, e a criação de programas de medidas socioeducativas em meio aberto, já apregoados pelo ECA, visando a desativação dos grandes complexos de internação. ${ }^{20}$

As medidas em meio aberto são valorizadas pelo ECA em razão de seu maior potencial educativo ligado às possibilidades de convivência com a família e comunidade, o que só pode ser viabilizado com a municipalização. Elas são assumidas pelo Sistema Único de Assistência Social (SUAS) a partir de 2008 (GOMES, 2012, p. 204). Em São Paulo são coordenadas pela Secretaria Municipal de Assistência Social (SMADS), por meio da Coordenadoria de Proteção Social Especial, e executadas por organizações sociais conveniadas, ${ }^{21}$ muitas das quais são integrantes ou passam a integrar o movimento social DCA. A composição do movimento se altera, aumentando a presença de entidades, organizações sociais instituídas juridicamente, conveniadas com o Estado.

A presença de entidades de atenção à criança e ao adolescente é histórica no movimento DCA, desde seus antecedentes internacionais, como, por exemplo, a atuação de Save the Children, desde 1919. No entanto, após a Convenção Internacional (CDC) e as

(CARDOSO, 2010, p. 161). Já em 1997 havia programas em meio aberto por meio de convênios entre organizações sociais e a Febem.

${ }^{19}$ Destacam-se a AMAR (Associação de mães), os Cedecas (Centros de Defesa da Criança e Adolescente), a ANCED (Associação Nacional de Cedecas) e a Conectas Direitos Humanos, organização não governamental internacional sediada em São Paulo.

${ }^{20}$ Segundo entrevista, em 1997 havia um convênio para "Liberdade Assistida Comunitária" firmado entre a Casa do Menor e a Febem, na zona Leste de São Paulo.

${ }^{21}$ São Paulo se caracteriza por sua rede socioassistencial com mais de $90 \%$ de organizações socia is privadas. Na Coordenadoria de Proteção Social Especial da Secretaria Municipal de Assistência (SMADS) estão os "serviços de medidas socioeducativas em meio aberto", num total de 55 serviços executados pelos convênios com organizações sociais. 
legislações que a seguem, como o ECA, nota-se a vinculação dessas entidades às políticas definidas pelo Estado. Por um lado, temos como avanço a publicização da atuação dessas entidades, que passam a seguir diretrizes públicas, que desafiam a superação da benemerência puramente privada. Por outro lado, essa participação societal na política pública pode ocorrer de forma ampla ou restrita.

González Bombal (2003, p. 352), analisando experiências latino-americanas de participação de organizações sociais em programas para crianças e adolescentes, encontra um "continuum que vai da participação com maior incidência", com organizações sociais "que participam nas diferentes fases, com uma ampla capacidade de transformar não só o desenho e a formulação das políticas como garantir transformações nas orientações das políticas", até as organizações "que limitam sua participação à implementação das políticas", com total dependência das diretrizes governamentais. ${ }^{22}$

Em São Paulo, há atualmente 55 convênios para a execução do "Serviço de Medidas Socioeducativas em Meio Aberto", gerenciados pela Secretaria Municipal de Assistência Social. Entre eles, encontram-se entidades, como o Cedeca Sapopemba, a Sociedade Santos Mártires, no Jardim Ângela, a UNAS - União de Núcleos, Associações e Sociedades de Moradores de Heliópolis e São João Clímaco, e o Centro Social Santo Dias, que participaram historicamente das lutas sociais e embates pela criação do ECA, contra os maus-tratos na Febem e pela construção da política socioeducativa em meio aberto.

Algumas delas, como o Cedeca Sapopemba, posicionam-se claramente: “a gente é uma entidade de controle social". É uma entidade ativa no Fórum regional de Sapopemba e faz parte da executiva da Articulação de entidades executoras de MSE - MA. No entanto, a coordenadora entrevistada aponta muitas dificuldades, no governo atual para o exercício do

22 González Bombal analisa seis estudos de caso, na Colômbia, Argentina e Brasil. Um deles, na Argentina, realizado por Carlos Acuña, aponta uma deficiente "participação comunitária" de organizações sociais em um programa de saúde materno-infantil, associada à dificuldade da equipe governamental em estimular e aceitar essa participação para além da mera consulta. No Chile, Gonzalo Delamaza também localiza organizações e grupos que "colaboram" em ações de saúde preventiva, mas não participam do debate da política da saúde e, mais amplamente, da implementação de serviços "externalizados", por meio de programas executados por ONGs, as quais perderam muitas vezes sua autonomia e seu potencial crítico na medida em que se orientaram para objetivos governamentais (apud ALBUQUERQUE, 2007, p. 39, 41). 
controle social. "Os relatórios que a gente manda" para a prefeitura, segundo ela, são instrumentos "de controle social". Mas quando esses relatórios apontaram críticas, foram devolvidos para a retirada dessas críticas. "Chegaram ao ponto de pedir aos [demais] gerentes para não se sentarem ao nosso lado". Algumas possibilidades permanecem, quando a supervisão é realizada por uma pessoa mais sensível e democrática, "que vem para construir". Finalmente, em função de alguns relatórios enviados por esse serviço de MSE, a coordenadora do Cedeca relata que "conseguiu abrir um procedimento verificatório", isto é, nota-se que houve alguma possibilidade de autonomia no exercício do controle social.

Esta entrevista aponta mais uma vez para a dificuldade em manter uma postura autônoma frente a um governo cujo projeto político vê o conveniamento numa perspectiva neoliberal como mera terceirização de uma função pública para uma entidade privada executora. Ao contrário, a entrevistada aponta uma ampla interação no governo de Marta Suplicy, com a secretária Aldaíza Sposati, com quem o Cedeca participou do desenho e execução de um projeto piloto para as medidas em meio aberto. Quem coordenou a elaboração desse projeto foi um ativista do movimento, em outro Cedeca, que nesse período trabalhou na Secretaria Municipal de Assistência. O Cedeca Sapopemba não depende totalmente dos recursos do governo municipal, mantendo vínculos com o governo federal e com a cooperação internacional, o que parece ser elemento essencial para a manutenção de sua postura crítica, conflitiva e autônoma.

O corporativismo também é apontado como um dos fatores que corroem a "rebeldia", e o repertório de confronto, das entidades institucionalizadas. Segundo um dos entrevistados, são priorizadas as lutas pelos "reajustes das verbas" destinadas aos convênios, e algumas organizações entram no conselho "de olho no Fundo [municipal DCA]". É apontado também que frequentemente uma instituição que era "combativa nos movimentos sociais, depois que ganhou responsabilidade jurídica, fica mais responsável, compromete o tempo" surge "receio" [...]. "Toda a energia vai para a execução" e não para "a elaboração e o controle".

Aqui emerge um último tópico, um dos "nós" que comprometem a vitalidade do movimento, o tempo e a energia dos ativistas que estão nas entidades conveniadas "vão para a execução" e não para "a elaboração e o controle" das políticas. O mesmo entrevistado 
observa que "ampliou-se a dependência financeira" do Estado, as organizações ficam mais "vulneráveis" e são "sugadas" por tais relações. "Hoje a política é definida pelo Estado", as organizações vivem em função dos "editais".

Mesmo com a dependência financeira, e a vulnerabilidade que faz com que essas organizações vivam em função da execução de programas, cerca de 30 organizações executoras de MSE-MA participam de uma "articulação" independente do Estado, na qual discutem sua incidência na política pública socioeducativa. No entanto, podemos notar, por meio das entrevistas, que aprender a lidar com a execução de programas e com o aparato estatal exige enorme esforço dos atores sociais.

\section{"Nós" e desafios - dilemas do aprendizado}

Entre as conclusões deste ensaio, objetiva-se apontar em primeiro lugar como é fértil a tensão entre atores e autores. Não encontra-se uma oposição, mas uma tensão que desafia uns e outros. Os autores que estudam a ação coletiva enfatizaram historicamente movimentos puramente societais, que se moveriam no "mundo da vida", privilegiando repertórios de confronto com o Estado. Mediante a fala dos atores, foi possível descobrir uma contínua articulação entre repertórios de ação institucionais e extrainstitucionais, assim como repertórios de confronto e repertórios de interação colaborativa entre Estado e sociedade. Percebe-se, ainda, a presença de ativistas que atravessam as fronteiras entre Estado e sociedade.

Para além da associação imediata entre institucionalização e "apelegamento" do movimento, marcado pela ação corporativa e pela cooptação, a fala dos atores conduziu para identificar que as ameaças de "enfraquecimento" do movimento se escondem em diversas amarras, ou "nós", como as dificuldades em lidar com a lógica institucional do Estado, com os interesses e projetos políticos dos partidos e governos, com os interesses e contingências das organizações.

Destaca-se a presença tanto dos atores e ações societais como os institucionais. Essas duas formas de ação são históricas, continuadas e valorizadas pelos atores sociais que as 
pleitearam. Como aponta José Szwako (2012), eles não pretendem abandonar a participação institucional. Ela não está necessariamente associada ao risco de "pelegar".

No entanto, a participação institucional dos movimentos apresenta dilemas que são identificados pelos atores. Salienta-se aqui alguns "nós", ameaças e dilemas que se escondem dentro da complexa questão da "institucionalização" e que restam como desafios de pesquisa.

\section{Projetos e interesses políticos dos atores da "sociedade política"}

Com o avanço da institucionalização democrática, os atores sociais do movimento se aproximam dos atores da sociedade política - os partidos e o Estado. Abrem-se espaços institucionais de participação e os atores se tornam mais institucionalizados, convertem-se muitas vezes em entidades com responsabilidades jurídicas e com vínculos contratuais com o Estado. Relacionam-se, assim, de forma mais intensa com atores fortemente engajados na viabilização de seus projetos e interesses políticos, como os partidos e grupos políticos dentro e fora do Estado.

Essa proximidade tem consequências para o bem e para o mal. Um entrevistado reconhece o "valor do PT dar prioridade" para a eleição do CMDCA, mas aponta que isso se tornou um "desserviço" ao movimento, pois o debate aconteceu "mais no setorial do que no Fórum".

As represálias, as proibições, a cooptação, a dependência financeira e material, as chapas do PSDB, a chapa e as articulações do setorial DCA do PT aparecem claramente apontando que aí há um "nó" que ameaça a autonomia do movimento.

\section{0 apoio dos atores societais que que são parceiros de projeto político}

A subordinação em relação ao Estado é associada por diversos atores à dependência financeira. Para escapar da dependência em relação aos atores políticos, os atores societais apontam a importância do apoio de outros parceiros societais que no passado se fizeram mais presentes. Entre eles, no plano do financiamento, aparecem as organizações de cooperação 
internacional, que compartilham seu projeto político com o movimento, que garantiram e ainda garantem a atuação autônoma de diversos atores, como pôde ser visto anteriormente.

A falta de apoio político de organizações mais fortes, estatais e societais, como Conectas, UNICEF, Ilanud, OAB, Abrinq e Universidades, que estiveram mais presentes em outros momentos, também é sentida como perda, que hoje fragiliza o movimento. Da mesma forma, destacou-se a importância da Igreja, especialmente a força da Teologia da Libertação, das pastorais e das CEBs, hoje mais frágil. Aqui se destaca a importância da educação popular desenvolvida nas CEBs, visto que muitos dos ativistas que "não largam o osso", apesar de todas as dificuldades, vieram dessa militância e destacam as concepções metodológicas aí adquiridas.

\section{O estado democrático de direito, sua burocracia e sua lógica institucional}

Em uma das reuniões do Fórum municipal, em 2012, um militante avalia:

Não estamos sabendo lidar com este Estado democrático de direito. [...] Acho que a sociedade não sabe onde quer ir. [Está] sem rumo. Lutou porque queria o Estado democrático de direito e agora... ${ }^{23}$

As dificuldades em lidar com os trâmites e burocracias institucionais aparecem nas relações entre Conselho e governo, como no caso da renúncia dos ativistas do movimento em 2003; ou na preparação das Conferências em 2011; na dificuldade de lidar com editais ("os editais é de enlouquecer", afirma um dos entrevistados) e na absorção de tempo e de energia para a execução dos convênios. Nas entrevistas são apresentadas questões quanto aos formatos das licitações, dos conselhos, das eleições. Avalia-se que há programas públicos cujo "desenho" é bom, mas cuja execução apresenta problemas: no "modo de gerenciamento, nas técnicas administrativas", problemas porque faltam "ferramentas" ou faltam "recursos de orçamento". Todos esses aspectos da institucionalização da política pública absorvem extremamente os atores societais, especialmente aqueles que executam programas públicos, e eles muitas vezes se sentem "cansados" frente ao pouco resultado de seu investimento.

\footnotetext{
${ }^{23}$ Conselheiro Tutelar de Guaianases, São Paulo, intervenção em reunião do FMDDCA em 4/2/2012.
} 
Esse cansaço pode estar ligado, como Sidney Tarrow adverte, ao "ritmo glacial" que parece caracterizar a "mudança social":

Os efeitos dos ciclos de confronto são indiretos e em grande parte imprevisíveis. Eles operam através de processos capilares sob a superfície da política, conectando os sonhos utópicos, as solidariedades inebriantes e a retórica do pico do ciclo ao ritmo glacial da mudança social (TARROW, 2009, p. 220).

Seria o atual, um momento de menos confronto e visibilidade do movimento? Um momento mais voltado para "dentro", em que muitos atores estão profundamente voltados para fazer, executar, experimentar, aprender? Um momento de absorver e operacionalizar sucessos e conquistas, de aprender a lidar com conselhos, conferências, tramitações, licitações, convênios, com o "Estado democrático", com os novos instrumentos de política pública?

Tarrow (2009, p. 259) afirma que, "nos estados democráticos os movimentos aprenderam a combinar a ação institucional e a extra-institucional" e aponta a alternância entre os "picos de confronto" e os momentos "mais apegados à rotina". Teria também este aprendizado um "ritmo glacial"?

Este ensaio ainda deixa como desafio de pesquisa desemaranhar esses "nós", ameaças e dilemas que se escondem dentro da complexa questão da "institucionalização".

\section{Referências}

ABERS, R.; BÜLOW, M. von. Movimentos sociais na teoria e na prática: como estudar o ativismo através da fronteira entre Estado e sociedade? Sociologias, Porto Alegre, ano 13, n. 28, set./dez. 2011, p. 52-84.

; SERAFIM, L.; TATAGIBA, L. A participação na era Lula: repertórios de interação em um Estado heterogêneo. In: 35 ENCONTRO ANUAL DA ASSOCIAÇÃO NACIONAL DE PÓSGRADUAÇÃO E PESQUISA EM CIÊNCIAS SOCIAIS - ANPOCS, 35, Caxambu - MG, 2011.

ALBUQUERQUE, M. do C. A. Eppur si muove: os movimentos sociais e a construção da democracia no Brasil. 1997. Dissertação. (Mestrado em Ciência Política) - Universidade Estadual de Campinas, Campinas, 1997. Disponível em:

<http://www.bibliotecadigital.unicamp.br/document/?code=vtls000117395\&opt=1> Acesso em 12/07/2012. 
A participação da sociedade na redefinição de políticas de direitos. Os direitos da Infância e o direito à moradia em países do Cone Sul na virada para o século XX. 2008. Tese. (Doutorado em Integração da América Latina) - Universidade Estadual de São Paulo, São Paulo, 2008. Apresentada ao PROLAM/USP.

. A participação da sociedade civil na construção de uma política de direitos da criança e adolescente no Cone Sul da América Latina. In: LIBERATI, Wilson Donizeti. Gestão da Política de Direitos ao adolescente em conflito com a Lei. São Paulo: Letras Jurídicas. 2012.

ALMEIDA. C. C. R. Sociedade civil, diversificação de atores e de modalidades de ação. Em Debate, Belo Horizonte, v.3, n.4, p.8-13, dez./2011.

CARDOSO, A. P. Sociedade Civil, Direitos Humanos e Adolescente em Conflito com a Lei. 2010. Dissertação (Mestrado em Políticas Públicas) - Universidade Bandeirante de São Paulo, UNIBAN, São Paulo, 2010.

. Sociedade Civil, Direitos Humanos e Adolescente em Conflito com a Lei. Revista Brasileira Adolescência e Conflitualidade, 2011 (3): 90-116.

CARLOS, E. Movimentos sociais e instituições participativas: efeitos organizacionais, relacionais e discursivos nos padrões de ação coletiva. In: II Seminário discente da PósGraduação em Ciência Política da USP, São Paulo, 2012.

DAGNINO, E.; PANFICHI, A.; OLVEIRA, A. Para uma outra leitura da disputa pela construção democrática na América latina. In: América Latina. São Paulo: Paz e Terra, 2006. . (Org.). A Disputa pela construção democrática na

FNDCA - Fórum Nacional de Defesa da Criança e do Adolescente. 2010. Incidência da sociedade civil na garantia dos direitos da criança e do adolescente. Plenária de políticas públicas. Brasília. Disponível em: <http://www.forumdca.org.br/arquivos/documentos>. Acesso em: 25/7/2011.

GOMES, M. do R. C. de S. A relação SUAS/SINASE na execução das medidas socioeducativas em meio aberto: notas para o debate. In: LIBERATI, Wilson Donizeti. Gestão da Política de Direitos ao adolescente em conflito com a Lei. São Paulo: Letras Jurídicas, 2012.

GONZÁLEZ BOMBAL, I. Organizaciones de la Sociedad Civil e incidencia en políticas públicas: reflexiones para seguir avanzando. In: ; VILLAR, R. (compiladores). Organizaciones de la Sociedad Civil e incidencia en políticas públicas. Buenos Aires: Libros del Zorzal, 2003

GURZA LAVALLE, A.; ISUNZA VERA, E. Precisiones conceptuales para el debate contemporáneo sobre la innovación democrática: participación, controles sociales y representación. In: (Org.). La innovación democrática en América Latina. Tramas y nudos de la representación, la participación y el control social. México: Centro de 
Investigaciones y Estudios Superiores em Antropología Social, Universidad Veracruzana, 2010.

PEREIRA, R. F. de S. Movimento de defesa dos direitos da criança e do adolescente: do alternativo ao alterativo. Dissertação (Mestrado em Serviço Social), Pontifícia Universidade Católica de São Paulo, São Paulo, 1996.

PAOLI. M. C. Movimentos Sociais no Brasil: Em busca de um estatuto político. In: HELLMANN, M. Movimentos sociais e democracia no Brasil. "Sem a gente não tem jeito". São Paulo: Editora Marco Zero: ILDESFES - Instituto Latino-americano de Desenvolvimento Econômico e Social. 1995.

SÃO PAULO. Diário Oficial do Estado de São Paulo (DOSP). Fórum Municipal de Defesa dos Direitos da Criança e do Adolescente. Documento de Esclarecimento de 18/03/2003. Publicado em 09 de abr./2004.

SCHERER-WARREN, I.; LÜCHMANN, L. H. H. Movimentos sociais e participação institucional: introduzindo o debate. Política e sociedade, Florianópolis, v. 10, n. 18, abr./2011.

SZWAKO, J. Participar vale a pena, mas...: a democracia participativa brasileira vista pelas lentes da utopia. In: Novas Lentes sobre a Participação: utopias, agendas e desafios. Revista Pólis. n. 52, 2012.

TARROW, S. O poder em movimento. Movimentos sociais e confronto político. Petrópolis: Editora Vozes, 2009.

TATAGIBA, L. F. A questão dos atores, seus repertórios de ação e implicações para o processo participativo. In: PIRES, R. R. C. (Org.). Efetividade das instituições participativas no Brasil: estratégias de avaliação. Brasília: Ipea, 2011. (Diálogos para o desenvolvimento v.7).

Entrevistas

Entrevista 1. Ex Conselheiro Tutelar (92), Fórum regional Capela do Socorro e Fórum Municipal.

Entrevista 2. Integrante do CMDCA por duas vezes, coordenador do FMDCA.

Entrevista 3. Ex-militante dos movimentos sociais. Coordenadora do Serviço de MSE - MA do Centro Santo Dias.

Entrevista 4. Professor. Ex Conselheiro Tutelar da primeira gestão. Integrante do Fórum regional do Butantã. Ativista desde os anos 80 .

Entrevista 5. Coordenadoria de Proteção Social Especial. 
Entrevista 6. Coordenador de organização social de atendimento a adolescentes. Exintegrante e ex-presidente do CMDCA. Ativista das CEBs e pastorais desde os anos 80. Integrante do Fórum regional de São Mateus. Ativista desde os anos 80.

Entrevista 7. Coordenador de Cedeca e serviço MSE - MA. Ativista das CEBs e pastorais desde os anos 80 . Integrante do Fórum regional de Sapopemba. Ativista desde os anos 80.

Recebido em: 23/10/2012

Aprovado em: 30/11/2012 